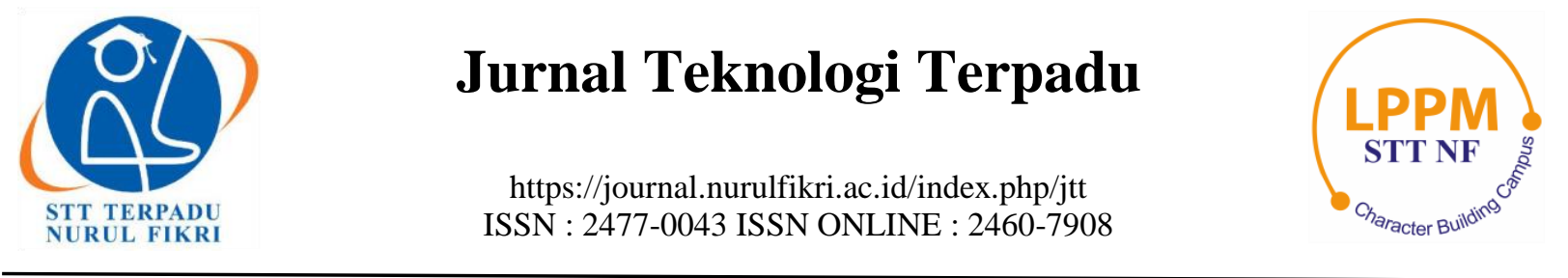

\title{
PENERAPAN COMPUTER VISION MENGGUNAKAN METODE DEEP LEARNING PADA PERSPEKTIF GENERASI ULUL ALBAB
}

\author{
Imamul Arifin ${ }^{1}$, Reydiko Fakhran Haidi ${ }^{2}$, Muhammad Dzalhaqi ${ }^{3}$ \\ 1,2.3 Departemen Teknik Informatika dan Komputer, Politeknik Elektronika Negeri Surabaya \\ Surabaya, Jawa Timur, Indonesia \\ imamul@pens.ac.id, reydikohaidi12345@ds.student.pens.ac.id,dzalhaqi@ds.student.pens.ac.id
}

\begin{abstract}
Machine learning is one of the applications of artificial intelligence. The use of machine learning in computer vision is closely related to deep learning where computer scientists get inspiration about deep learning technology from the environment. The purpose of the research in this manuscript is to know and understand deep learning technology along with simple examples in processing image objects and to know and understand artificial intelligence technology from the perspective of the ulul albab generation so that it can provide comprehensive benefits for the world. The research conducted in this paper is a type of qualitative research with library research using various books and other reading literature such as journals and special websites so as to produce information on the topic under study. Artificial intelligence technology will always develop and lead to increasingly sophisticated directions, but technology also has a negative impact. The Ulul Albab generation must be able to struggle to have a positive impact on society because the Ulul Albab generation is the hope for the progress of Islamic civilization in various sectors of science and technology.
\end{abstract}

Keywords: Artificial Intelligence Systems, Machine learning, Computer vision, Deep learning

\begin{abstract}
Abstrak
Machine learning merupakan salah satu penerapan kecerdasan buatan. Penggunaan machine learning pada computer vision erat berkaitan dengan deep learning yang mana para ilmuwan komputer mendapatkan inspirasi mengenai teknologi deep learning dari alam sekitar. Tujuan penelitian pada naskah ini adalah Mengetahui dan memahami teknologi deep learning beserta contoh sederhana dalam pemrosesan objek gambar dan Mengetahui dan memahami teknologi kecerdasan buatan dalam perspektif generasi ulul albab sehingga bisa memberikan manfaat secara menyeluruh bagi dunia. Penelitian yang dilakukan pada karya tulis ini merupakan jenis penelitian kualitatif dengan metode studi pustaka (library research) menggunakan berbagai buku dan literatur bacaan lainnya seperti jurnal dan website khusus sehingga menghasilkan informasi dari topik yang diteliti. Teknologi kecerdasan buatan akan selalu berkembang dan menuju arah yang semakin canggih, tetapi teknologi juga mempunyai dampak negatif. Generasi Ulul Albab harus bisa berjuang untuk memberikan dampak positif bagi masyarakat karena sejatinya generasi ulul albab adalah harapan kemajuan peradaban islam di berbagai sektor ilmu pengetahuan dan teknologi.
\end{abstract}

Kata kunci: Sistem Kecerdasan Buatan, Machine learning, Computer vision, Deep learning

\section{PENDAHULUAN}

Teknologi merupakan hal yang sangat penting bagi kehidupan peradaban manusia, khususnya komputer. Dengan berbagai teknologi komputer yang ada sekarang, segala urusan manusia hampir di berbagai belahan dunia menjadi lebih mudah baik dalam berkomunikasi, kegiatan edukasi hingga memecahkan permasalahan yang rumit seperti perhitungan statistik. Hal ini tidak terlepas dari berbagai peristiwa persaingan manusia di bumi.
Di abad ke-21 ini, teknologi telah mencapai puncak tertinggi dalam sejarah umat manusia. Hal ini dapat diketahui dengan munculnya artificial intelligence khususnya di bidang computer vision di berbagai sektor industri salah satu contohnya mobil listrik dengan sistem autopilot. Teknologi tersebut sangat berguna di berbagai bidang ilmu pengetahuan dan tidak hanya terdapat pada industri otomotif. Dengan metode pengolahan data atau citra yang tanpa pemrograman secara eksplisit membuat salah satu cabang artificial intelligence, yaitu machine learning memiliki fungsi yang lebih spesifik dalam mengolah data 
gambar, diantaranya dengan menggunakan pemprosesan secara deep learning.

Kemajuan teknologi tersebut yang tumbuh begitu pesat merupakan dampak dari era revolusi industri 4.0 saat ini yang mana pada masa ini kehidupan manusia sangat bergantung pada teknologi yang bisa memberikan kemudahan dalam setiap urusan. Namun, kemudahan dalam mengakses teknologi yang malah semakin membuat ilmu pengetahuan dan teknologi serta ilmu agama tidak memiliki keharmonisan dalam pengembangannya. Seolah bahwa agama hanyalah masalah akhirat dan tidak perlu dikaitkan dalam pengembangan teknologi di dunia (sekuler).

Sudah seharusnya generasi ulul albab memiliki sifat ilmuwan dan religius sehingga bisa memadukan keimanan, ketaqwaan, kritis, berpikiran terbuka, dan menggunakan akalnya semaksimal mungkin. Kemajuan ilmu pengetahuan dan teknologi yang tidak diiringi dengan peningkatan dan pengukuhan keimanan dan ketaqwaan maka akan menimbulkan masalah seperti dampak negatif. Sebaliknya jika diiringi dengan keimanan dan ketaqwaan maka tentunya kemajuan ilmu pengetahuan dan teknologi (iptek) dapat memberikan manfaat serta menjadi salah satu indikator kesuksesan umat islam dalam menggabungkan aspek ilmu dunia dan akhirat.

Sebagai generasi milenial muslim yang hidup di era modern seperti ini, sudah selayaknya kita menggabungkan aspek ilmu pengetahuan dan teknologi dengan memahaminya dengan lebih banyak membaca literatur yang spesifik seperti yang kemudian diiringi dengan peningkatan keimanan dan ketaqwaan sehingga kita bisa menjadi salah satu kontributor dalam memajukan peradaban islam di masa modern ini serta bisa menjadikan segala ciptaan Allah SWT sebagai sumber dalam mengembangkan ilmu pengetahuan. Oleh karena itu, kita wajib untuk belajar dan menguasai sains teknologi serta ilmu agama.

Tujuan dari penelitian ini untuk memberikan akses literasi kepada pembaca terkait teknologi yang sedang marak dikembangkan, yaitu deep learning. Penelitian ini juga bertujuan untuk mengetahui dan memahami teknologi kecerdasan buatan dalam perspektif generasi ulul albab sehingga bisa memberikan manfaat secara menyeluruh bagi dunia.

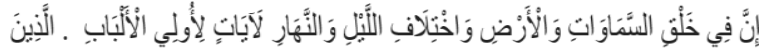

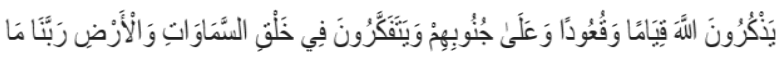

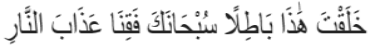

Pada ayat tersebut, Allah telah menjelaskan bahwa Dia memberikan tanda-tanda penciptaan bagi orang yang berakal dan mau berpikir mengenai makna dibalik penciptaan. Sungguh segala ciptaan Allah SWT tidak ada yang sia-sia. Rumusan masalah yang dibahas pada penelitian ini meliputi: (1) Bagaimana mekanisme kerja teknologi deep learning pada penerapannya di computer vision?; (2) Bagaimana generasi ulul albab memahami, mempelajari, dan mengembangkan teknologi digital khususnya yang berbasis kecerdasan buatan seperti deep learning agar bisa memberikan manfaat?

\section{METODE PENELITIAN}

2.1 Tipe Penelitian

Penelitian yang dilakukan pada karya tulis ini merupakan jenis penelitian kualitatif dengan metode studi pustaka (library research) menggunakan berbagai buku dan literatur bacaan lainnya seperti jurnal dan website khusus sehingga menghasilkan informasi dari topik yang diteliti. Pendekatan kualitatif memerlukan analisis deskriptif. Analisis deskriptif dilakukan untuk memberikan penggambaran sederhana terkait mekanisme kerja deep learning dan penerapannya pada computer vision serta memberikan penjelasan terhadap generasi ulul albab dan dampak positif dan negatif dari perspektif generasi ulul albab.

\subsection{Teknik Pengambilan Data}

Dalam penelitian kualitatif dengan pendekatan kepustakaan (library research), teknik mengumpulkan data dilakukan dengan mengoleksi data penelitian berupa informasi dari buku, jurnal, dan website khusus yang membahas mengenai artificial intelligence, machine learning, deep learning serta penerapannya di bidang computer science serta mengenai topik generasi ulul albab yang telah dicari, diseleksi (organizing), dan dianalisis (finding). Pencarian sumber data penelitian ini dilakukan dengan mencari data yang memerlukan tindakan pengolahan secara teoritis dan studi pustaka yang digunakan tidak memerlukan pengujian empirik. Data yang ditampilkan berupa informasi teori dari kajian yang telah diolah menjadi lebih ringkas dan sistematis.

\subsection{Teknik Analisis Data}

Penelitian jurnal ini memanfaatkan teknik analisis isi (content analysis) secara ilmiah terkait topik yang dibahas sehingga memberikan penjelasan dan pendeskripsian terkait penerapan deep learning pada computer vision serta perspektif generasi ulul albab.

\section{HASIL DAN PEMBAHASAN}

\subsection{Pemahaman Dasar Mengenai Deep Learning dan Machine Learning}

Deep learning merupakan salah satu cabang ilmu machine learning yang utamanya berdasarkan Artificial Neural Networks, sedangkan machine learning merupakan program komputer yang mana program tersebut akan mengotomasi sistem kerjanya dengan belajar dari data yang digunakan dan tidak terprogram secara eksplisit untuk melakukan tugas tertentu dan ketiga hal tersebut memiliki keterkaitan dalam pengembangnya. 
Para penemu sering kali mencari dan mendapat ide dari alam. Wright bersaudara telah berhasil menciptakan pesawat yang pada waktu sebelumnya, mereka memperhatikan mekanisme anggota tubuh pada burung yang sedang terbang. Kemudian terdapat penemuan inovasi transportasi laut, yaitu kapal selam yang mana bentuk kapal selam banyak mendapatkan inspirasi dari bentuk tubuh paus dan hewan laut yang sejenisnya.

Hal ini yang membuat teknologi machine learning dan jaringan saraf tiruan ditemukan oleh para ilmuwan. Mereka mendapatkan ide tersebut dari mekanisme kerja otak manusia. Menurut ilmuwan, otak manusia merupakan teknologi canggih yang telah terbenam pada organ tubuh manusia sehingga mereka ingin membuat teknologi yang bisa memiliki kecanggihan seperti otak manusia. Kita sebagai generasi Ulul Albab harus bisa mengikuti perkembangan teknologi saat ini, seperti mempelajari tentang Deep learning. Tujuan generasi Ulul Albab mengikuti teknologi adalah untuk mendapatkan manfaat seperti lebih Inisiatif, Inovatif, dan kreatif.

\subsubsection{Artificial Neural Network (ANN)}

ANN adalah model pembelajaran mesin yang serbaguna, kuat, dan sangat scalable karena ANN merupakan algoritma dasar dan juga metode sederhana yang digunakan dalam pendekatan Deep learning. Dengan kelebihannya tersebut, para praktisi komputer dan teknologi informasi menilai bahwa ANN merupakan teknik yang bagus untuk diterapkan dalam proyek mereka karena mudah dalam menyelesaikan permasalahan yang kompleks dan dapat mempersingkat waktu yang digunakan dalam pemrosesan data.Pada teknik ini operasi atau program yang dilakukan komputer meniru dan mereplikasi cara kerja sistem saraf manusia. Teknik ini biasanya menggunakan dua buah layer dalam penggunaan. Layer adalah lapisan yang menjadi titik-titik yang saling terhubung dengan kemungkinan berdasarkan bobotnya dan biasa disebut dengan perceptron.

Perceptron dapat diartikan sebagai komponen dasar pembangun jaringan saraf tiruan. Perceptron pertama kali digagas oleh ilmuwan yang bernama Frank Rosenblatt dari Cornell Aeronautical Library. Mereka membuat analogi pada ANN dan jaringan saraf otak manusia. Perceptron dan neuron merepresentasikan organ atau bagian yang memiliki fungsi yang hampir sama tetapi dengan penerapan yang berbeda, perceptron pada deep learning sedangkan neuron pada otak manusia.

\subsubsection{Struktur dan Cara Kerja Perceptron}

Perceptron menerima masukan berupa numerik yang kemudian data tersebut diolah hingga menghasilkan sebuah keluaran. Gambar 1 merupakan manifestasi dari cara kerja perceptron.

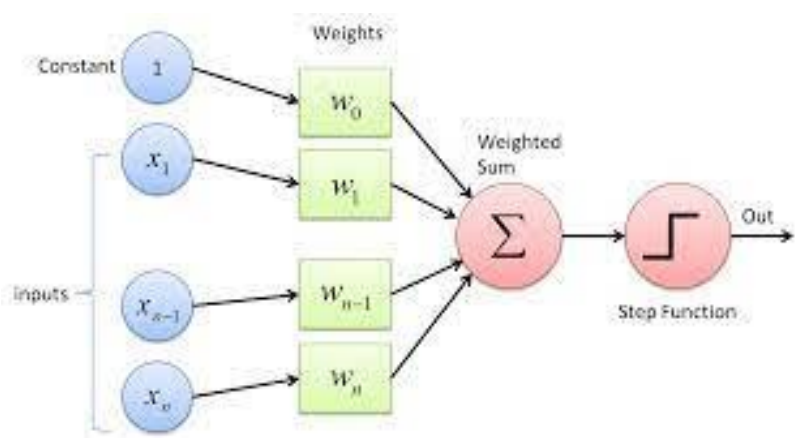

Gambar 1. Grafik Mekanisme Kerja Deep Learning [19]

Sebuah perceptron terdiri dari 5 komponen yaitu:

1. Input (xi)

2. Bobot atau weights (Wi) dan bias (W0)

3. Penjumlahan atau sum $\left(\sum\right)$

4. Fungsi aktivasi atau non linearity function $\left(\int\right)$

5. Output (y)

Berikut adalah tahapan perceptron dalam mengolah data dengan penjelasan seperti di bawah

- Pertama perceptron menerima inputan data atau informasi bertipe numerik

- Lalu setiap inputan memiliki bobot yang berbedabeda. bobot tersebut merupakan parameter yang akan menjadi acuan bagi perceptron untuk dipelajari yang juga menunjukkan kekuatan node tertentu

- Pada tahap penjumlahan, setiap inputan akan dikalikan dengan berat sesuai dengan komposisinya masingmasing kemudian dijumlahkan dengan estimasi nilai penyimpangan yang merupakan sebuah nilai yang tetap. Nilai estimasi (perkiraan penyimpangan) memberikan kemudahan bagi kita untuk mengatur kurva fungsi aktivasi sehingga bisa meminimalisasi kesalahan dalam membuat prediksi. Hasil pada bagian ini disebut weighted sum

- Selanjutnya yaitu menerapkan weighted sum pada fungsi aktivasi yang dinamakan oleh ilmuwan dengan nama Non-Linearity Function. Tujuan melakukan langkah ini adalah untuk memetakan nilai dari hasil (output) menjadi nilai yang diperlukan dalam prediksi model contohnya antara 0 sampai 1 atau -1 sampai 1 . Dengan adanya fungsi ini perceptron memiliki kemungkinan untuk bisa beradaptasi pada data yang tidak linear.

- Terakhir, output bisa didapatkan dari kalkulasi data yang telah diolah oleh perceptron

Sebelumnya telah disinggung terkait fungsi aktivasi dalam mekanisme kerja perceptron. Fungsi ini mempunyai peran untuk membuat jaringan syaraf tiruan memiliki kemampuan untuk menyesuaikan pola pada data yang tidak linier karena pada kehidupan yang nyata data yang terdapat di dunia lebih didominasi oleh data yang tidak linier. Berikut adalah rumus dalam menghitung fungsi aktivasi pada mekanisme kerja perceptron. 
Gambar 2 menunjukkan formula dalam menghitung keluaran model yang menggunakan deep learning. Output model merupakan hasil operasi dari penjumlahan estimasi (perkiraan penyimpangan) dengan total keseluruhan variabel atau fitur yang dikalikan dengan beratnya. Apabila model tidak linear maka perhitungan sebelumnya harus dikalikan dengan fungsi aktivasi non-linear.

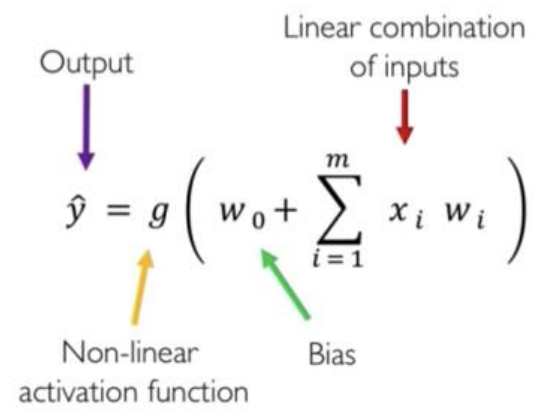

Gambar 2. Rumus untuk Mendapatkan Output dari Model Deep Learning [26]

Visualisasi data non linier lebih sering terjadi pada kasus di dunia nyata hal ini yang kadang selalu menjadi inputan pada pengolahan data dengan perceptron. Pada data dengan pola tersebut maka diperlukan fungsi aktivasi sehingga jaringan saraf tiruan dapat mengenali pola dengan melakukan beberapa metode, salah satunya adalah klasifikasi seperti pada Gambar 3. Tanpa fungsi aktivasi maka jaringan saraf hanya mengenali pola linier saja. Kombinasi deep learning dengan dengan fungsi aktivasi membuat program menjadi lebih efektif karena bisa mengestimasi fungsi kompleks eksponensial yang mana biasanya memiliki visualisasi data yang cukup kompleks.

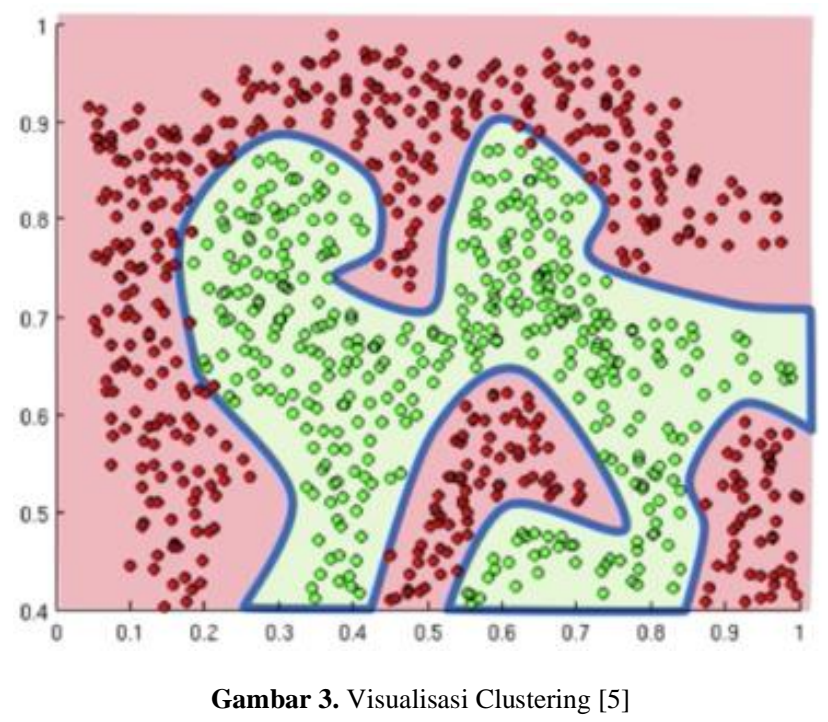

Oleh karena itu biasanya para praktisi akan melakukan pembersihan data baik secara analisis klasik ataupun modern (naive bayes) terkait data eksploratif serta memvalidasi model terbaik dan visualisasi yang sesuai dari beberapa kriteria menggunakan metode pada feature engineering.

\subsubsection{Fungsi Aktivasi pada Perceptron}

Fungsi aktivasi perceptron pada umumnya memiliki 3 jenis, yaitu fungsi sigmoid, fungsi hiperbolik, dan fungsi rectified linear unit (ReLU). Fungsi Sigmoid (logistic function) memiliki rentang output antara 0 hingga 1 dan biasa diterapkan untuk memprediksi sebuah kemungkinan pada model. Fungsi Sigmoid juga memberikan nilai prediksi yang lebih mendetail seperti pada Gambar 4.

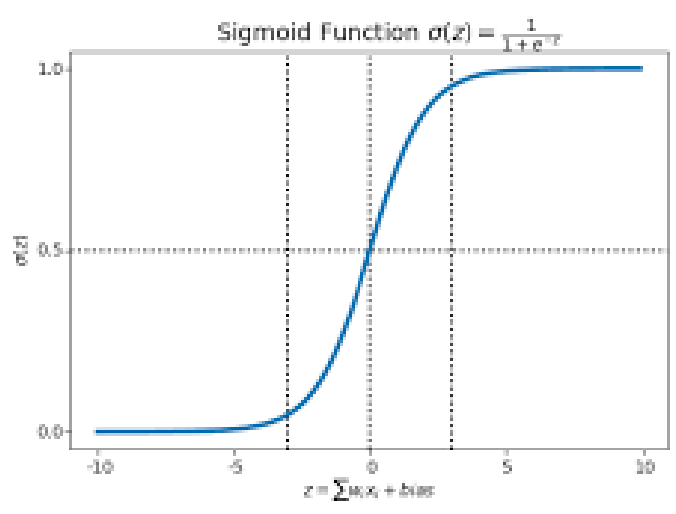

Gambar 4. Grafik Fungsi Sigmoid [3]

Pada Gambar 4 dapat dilihat bahwa nilai x jika kurang dari -2,5 memberikan akurasi prediksi yang mendekati angka 0 , sedangkan nilai x jika lebih 2,5 maka akurasi prediksi mendekati angka 1. Fungsi Hyperbolic Tangent (tanh) ini memiliki kemiripan bentuk dengan fungsi sigmoid, tetapi rentang pada fungsi ini bernilai antara -1 dan 1 . Akibat dari rentang tersebut hasil keluaran lebih banyak berpusat di sekitar 0 ketika data baru mulai dilatih. Sifat seperti ini biasa disebut dengan zero centered, sifat ini memudahkan pengembang dalam memprediksi sebuah model yang memiliki nilai sangat negatif, netral, dan sangat positif. Gambar 5 menunjukkan fungsi hyperbolic.

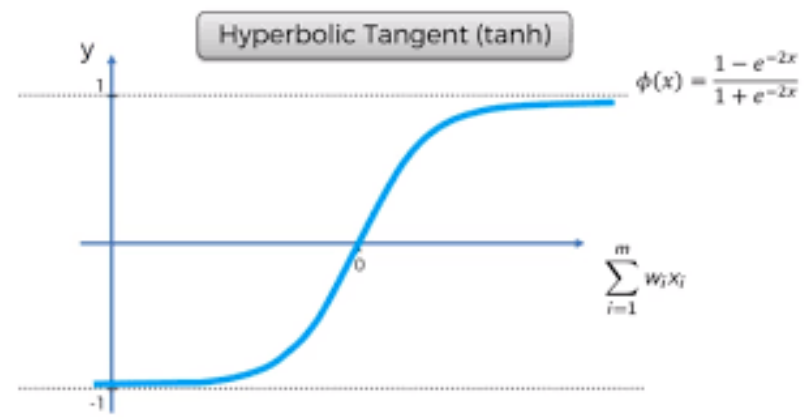

Gambar 5. Grafik Fungsi Hiperbolik [3]

Fungsi Rectified Linear Unit (ReLU) memiliki ciri khas sendiri dengan bentuk kemiringan yang tidak konsisten dan bisa berubah dengan tiba-tiba dengan nilai turunan bernilai 0 pada $\mathrm{z}<0$. Walaupun demikian, Fungsi ini biasanya dijadikan fungsi default (bawaan) karena fungsi ini bekerja sangat baik dan memiliki kemampuan untuk membuat jaringan saraf tiruan memprediksi model secara efisien sehingga waktu dalam pemrosesan data bisa lebih cepat. Gambar dari grafik dari ReLU ditampilkan pada Gambar 6. 


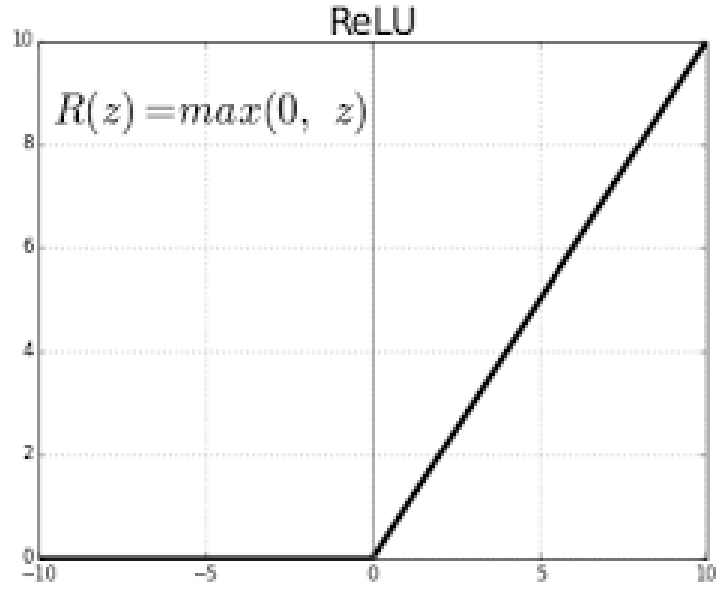

Gambar 6. Database Mirroring Architecture [5]

Berikut ini adalah beberapa perbandingan grafik dari fungsi aktivasi perceptron yang telah dibahas beserta beberapa turunan fungsinya yang juga sering digunakan dalam kegiatan memprediksi model.

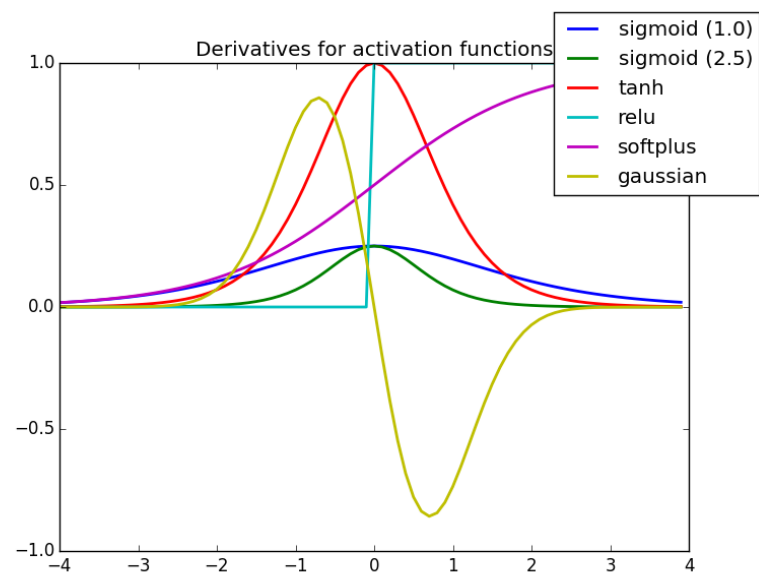

Gambar 7. Grafik kumpulan fungsi aktivasi [5]

\subsubsection{Ilustrasi Pemrosesan Data oleh Perceptron}

Bagian ini membahas mengenai perceptron menggunakan diagram pohon seperti pada Gambar 8.

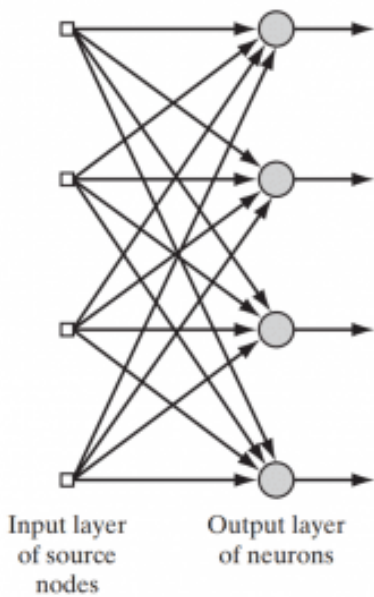

Gambar 8. Grafik Deep Neural Network [28]
Gambar 8 merupakan gambaran sederhana dari kerja perceptron sebab pada grafik tidak digambarkan bobot (w), melainkan hanya berupa $\mathbf{X}_{\mathbf{1}}, \mathbf{X}_{\mathbf{2}}, \mathbf{X}_{\mathbf{3}}$ dan $\mathbf{X}_{\mathbf{4}}$ adalah input atau layar sumber nodes, dan $\mathbf{Z}$ (terdapat 4 buah pada gambar) yang merupakan sebuah perceptron atau layar neuron. Kepadatan dari tiap inputan biasa dinamakan dengan dense yang diakibatkan oleh koneksi tiap inputan dengan perceptron itu sendiri. Dense layer atau lapisan padat merupakan sebuah lapisan yang tersusun atas dua buah perceptron atau lebih.

Dari konsep tersebut, timbul gagasan mengenai hidden layer yang merupakan dense layer yang terletak antara input dan perceptron. Pada Gambar 9 ditunjukkan contoh dari hidden layer.
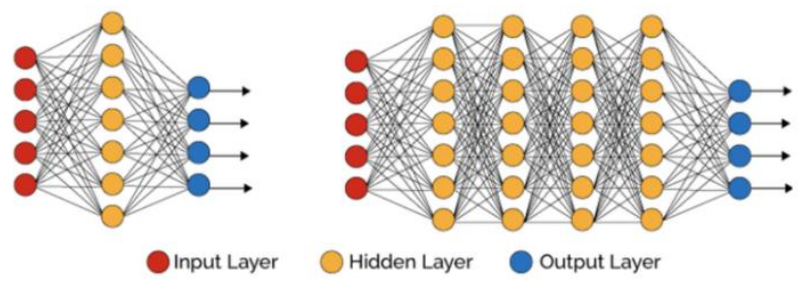

Gambar 9. Grafik Deep Neural Network dengan Hidden Layer [29]

Berdasarkan pada Gambar 9, bagian yang kiri hanya memiliki 1 hidden layer, sedangkan bagian yang kanan memiliki 4 hidden layer. Pada layer inilah terjadi hal-hal yang tidak bisa diintervensi oleh manusia. Secara sederhana hidden layers adalah lapisan fungsi matematika yang dirancang untuk menghasilkan output yang spesifik untuk hasil yang ditentukan. Pada ANN, lapisan (layer) input dan output merupakan bagian yang wajib ada, sedangkan hidden layer bersifat opsional. Baik hidden ataupun output layer memiliki perceptron yang terdiri dari minimal satu perceptron dan pada bagian input layer, data yang bertipe numerik akan ditampung sebelum diproses.

Sebuah layer dinamakan hidden layer karena sifatnya yang memang tersembunyi sehingga kita tidak bisa mengamati atau bahkan mengintervensi cara kerjanya. Hal ini berbalik dengan input layer dan output layer. Oleh karena itu semakin banyak hidden layer maka akan semakin lama sistem dalam memprediksi sebuah model, tetapi dengan begitu masalah yang kompleks pun dapat diselesaikan dengan cara yang lebih efisien dan efektif.

\subsection{Convolutional Neural Network (CNN)}

Convolutional neural network merupakan ANN yang lebih canggih. CNN biasa disebut dengan the state-of-the-art for image classification task. Berdasarkan metode ANN yang telah dijelaskan sebelumnya, $\mathrm{CNN}$ memberikan spesialisasi pada komputer salah satunya adalah untuk bisa melihat data secara visualisasi yang kemudian dianalisis. Metode ini memungkinkan komputer diprogram untuk memiliki pemahaman seperti manusia untuk menilai yang telah mereka pelajari yang kemudian diterapkan pada proses prediksi. Teknik ini biasa disebut dengan computer vision. 
CNN digagas oleh ilmuwan yang bernama Yann LeCun. Pada tahun 1998, gagasan ini dipublikasi dalam jurnal ilmiah yang berjudul "Gradient-Based Learning Applied to Document Recognition". Pada awal ditemukan CNN bernama LeNet (berasal dari kata LeCun) dan hanya memiliki kemampuan untuk mengenali tulisan tangan, tetapi dengan gambar yang resolusinya sangat kecil. Terdapat dua tahapan dalam memproses gambar menggunakan CNN. Tahap pertama adalah adalah klasifikasi gambar menggunakan feedforward dan tahap kedua adalah tahapan pembelajaran mesin dengan metode backpropagation. Backpropagation adalah prosedur untuk menyeimbangkan weight secara berulang untuk meminimalkan penyimpangan pada output.

\subsubsection{Cara Komputer Melihat Objek Gambar}

Telah disinggung sebelumnya bahwa deep learning memiliki teknik yang memberikan kemampuan pada komputer melihat dan memahami seperti manusia, yaitu dengan menerapkan teknik computer vision. Pada dasarnya komputer adalah benda mati berupa komponen elektronik coba dihidupkan oleh manusia dengan pengetahuan yang telah dimilikinya. Pada dasarnya komputer hanyalah sebuah perangkat elektronik yang hanya bisa membaca data biner yang kemudian dari data tersebut diolah sehingga menghasilkan data numerik yang lebih kompleks. Sebenarnya ketika manusia melihat foto pada perangkat elektronik itu merupakan representatif dari matrik 2 dimensi (pada foto monokrom) atau 2 x 3 dimensi (foto dengan warna dasar Red, Green, Blue). Ilustrasi komputer dalam memahami gambar ditampilkan pada Gambar 10.
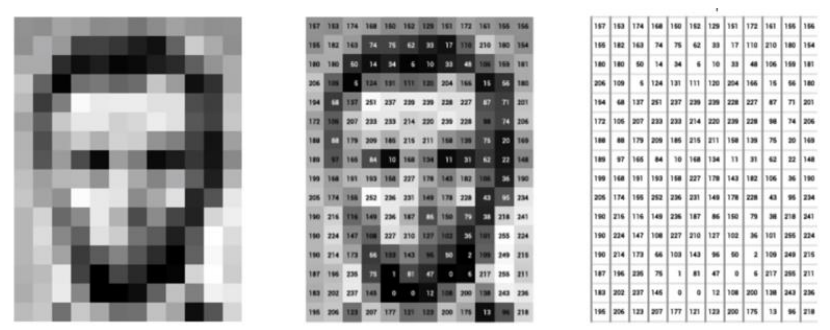

Gambar 10. Ilustrasi Transformasi Gambar Menjadi Pixel [11]

Ketika metode CV (computer vision) telah diterapkan pada komputer, komputer pun memiliki kemampuan untuk mengklasifikasikan gambar berdasarkan metode ANN berdasarkan probabilitas yang telah dibahas sebelumnya. Komputer dapat memprediksi siapa yang ada pada gambar tersebut berdasarkan data yang sudah diberikan sebelumnya. Pada metode klasifikasi gambar, kita harus mengetahui setiap atribut yang ada pada gambar. Hal ini bertujuan untuk memudahkan dan mempercepat komputer dalam menganalisa dan memprediksi gambar. Contoh tersebut ditunjukkan pada Gambar 11 yang mana pada setiap gambar memiliki atribut yang berbeda-beda begitu juga dengan prediksinya. Gambar dengan border berwarna merah diartikan bahwa gambar tersebut tidak memiliki atribut yang dipasangkan (False) dan gambar dengan border berwarna biru diartikan bahwa gambar memiliki atribut yang dipasangkan (True)

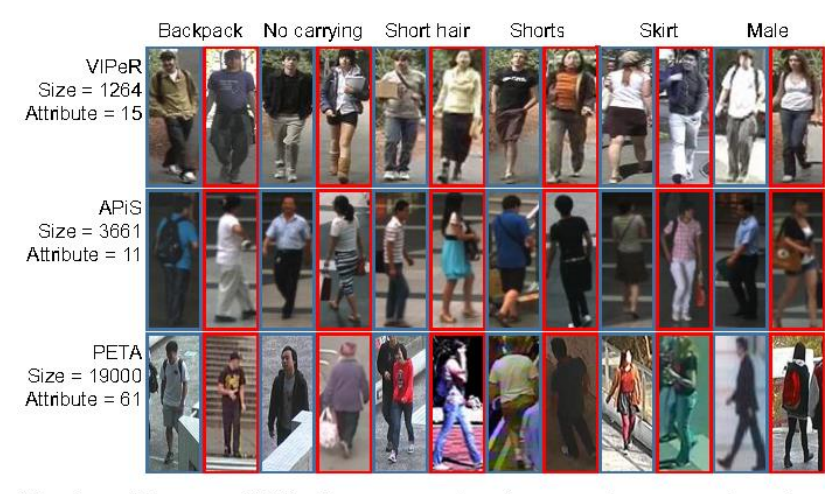

Fig. 1. The new PETA dataset contains far more images and attribute

Gambar 11. Contoh Computer Vision Yang Memprediksi Hasil Berdasarkan Atribut Yang Telah Dipasangkan [2]

\subsubsection{Convolutional Layer}

Telah diketahui bersama bahwa gambar yang dilihat komputer berupa piksel-piksel dalam bentuk matriks dengan dimensi tertentu. Namun, itu bukan satu-satunya metode yang dapat memberikan kemampuan pada komputer untuk mengenali gambar dan memprediksinya. Metode lain yang cukup efektif adalah dengan menggunakan convolutional layer. Sebuah metode yang memiliki fungsi untuk mengenali atribut pada objek gambar. Seperti pada struktur biologi di mana setiap sel yang digabung membentuk sebuah jaringan kemudian kumpulan jaringan membentuk organ dan kumpulan organ membentuk sistem organ yang pada akhirnya menjadi organisme. Pada komputer atribut yang lebih rendah merupakan bagian dari atribut yang lebih tinggi. Contoh sederhananya adalah atribut wajah dibentuk oleh atribut mata, hidung telinga, bibir dan lainnya.

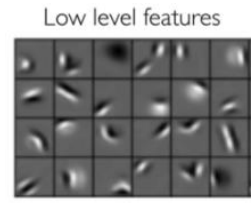

Edges, dark spots

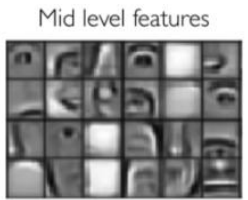

Eyes, ears, nose

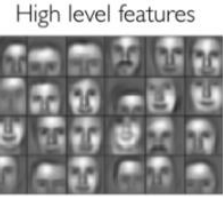

Facial structure
Gambar 12. Ilustrasi Penerapan Convolutional Layer Pada Computer Vision Dalam Melihat Objek Wajah [9]

Convolutional layer dapat mendeteksi layer karena menggunakan metode filter. Setiap instance filter yang berbeda akan mendeteksi dan menghasil matrik 3 x 3 yang berbeda pula. Ketika manusia mampu membedakan antara manusia dengan hewan atau tumbuhan berdasarkan bentuknya, maka komputer membedakannya berdasarkan matrik dari hasil filter sebuah objek, seperti pada Gambar 13. 


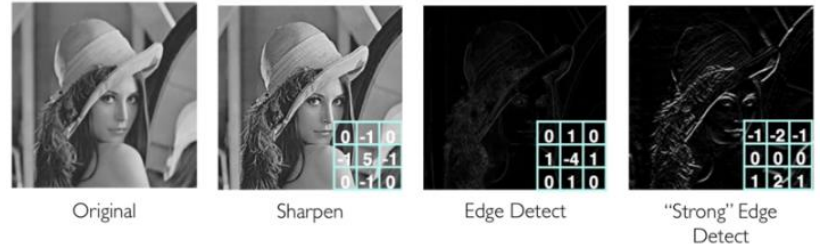

Gambar 13.Contoh Penerapan Filter yang Ditransformasi Menjadi Matrik [11]

Filter pada pemprosesan gambar terdapat beberapa jenis diantaranya filter secara linear dan non-linear seperti Gaussian Filter, Median Filter, Mean Filter, dan Weiner Filter. Proses konvolusi menjelaskan bagaimana suatu gambar atau objek bisa memiliki matrik dengan nilai dan bobot tertentu pada penggunaan filter. Pada proses ini akan dilakukan perkalian antara matrik objek berdasarkan resolusi dengan area pada objek serta hasil dari proses konvolusi terhadap objek. Ketika proses ini selesai maka hasilnya dapat dijadikan input dalam memprediksi gambar tersebut. Hal ini hampir mirip dengan data pre-processing, tetapi berbeda metode. Ilustrasi dari proses konvolusi digambarkan pada Gambar 14.

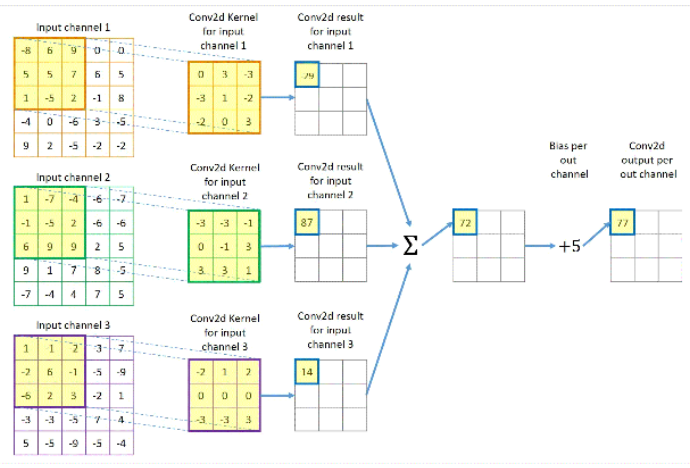

Gambar 14. Ilustrasi Proses Konvolusi [23]

Setelah dilakukan proses konvolusi, jaringan saraf tiruan akan dilakukan metode max pooling, yaitu sebuah teknik untuk mengurangi resolusi objek yang dianalisis, tetapi tetap mempertahankan informasi dan data pada objek. Contohnya ialah resolusi gambar diturunkan sampai batas tertentu sehingga tidak mengubah data objek.

Proses kalkulasi dalam teknik ini sama seperti filter yaitu menggunakan matrix yang nantinya merepresentasikan objek gambar yang telah diturunkan resolusinya. Pada Gambar 15 adalah contoh perhitungan metode max pooling.

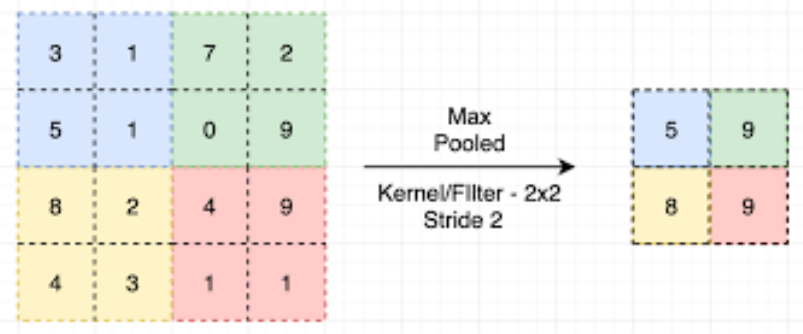

Gambar 15. Ilustrasi Perhitungan Max Pooling pada Proses Konvolusi [23]
Dari semua penjelasan mengenai mekanisme kerja komputer dalam melihat dan memahami gambar sebenarnya banyak sekali metode ataupun algoritma yang bisa digunakan dalam mengklasifikasikan gambar, contohnya adalah capsule network. Namun, pada pembahasan ini hanya dijabarkan hal-hal yang sifatnya umum dan mendasar sehingga dapat memberikan gambaran secara mudah kepada para pembaca mengenai teknologi deep learning yang mencoba meniru cara kerja otak manusia. Dalam hal ini yang dibahas adalah cara komputer mengklasifikasikan gambar serta membuat prediksi dari gambar tersebut berdasarkan data dan pengalaman sistem tersebut.

Teknologi deep learning tidak hanya digunakan dalam proses pengklasifikasian gambar melainkan, sebab ada banyak sekali teknologi yang menggunakan metode ini seperti mengklasifikasi data sidik jari setiap orang dan lainnya. Pada jurnal ini, hanya dibahas satu yang menjadi dasar pemahaman mengenai mekanisme kerja deep learning pada objek berupa gambar.

\subsection{Sekilas Mengenai Generasi Ulul Albab}

Perkembangan teknologi tidak dapat kita pungkiri telah membawa kita dalam globalisasi ilmu serta budaya. Pengintegrasian ilmu di dalam dunia pendidikan sudah lama direncanakan, karena adanya kekhawatiran peranan lembaga pendidikan ketika menjawab problematika kemanusiaan yang kompleks dengan seiring perubahan pada dinamika sosial masyarakat dalam perubahan zaman. Islam merupakan agama yang sempurna telah memiliki pegangan yang jelas mengenai tujuan dan hakikat Pendidikan dengan mengembangkan potensi fitrah manusia secara utuh baik jasmani maupun rohani. Persoalan yang terjadi pada umat islam disebabkan oleh kurangnya penghayatan dalam falsafah hidup pada umat islam.

Sering kali kita lihat sekarang ini umat islam lebih bangga mengikuti falsafah hidup dunia barat dan tidak berpegang pada Al-Quran yang seharusnya menjadi tuntunan umat Islam. Sesungguhnya di dalam Al-Quran dan sunnah terdapat nilai-nilai yang mengarahkan umat islam dalam memahami pengetahuan dunia dan akhirat. Hal ini dapat dilihat dari kebanyakan ayat Al-Qur'an mengandung konteks pendidikan baik ilmu dunia maupun akhirat yang akan bermanfaat bagi umat manusia. Diantaranya terkait makna pendidikan yang islami, yang pada hakikatnya adalah pelaksanaan dari ajaran agama Islam yang tidak memisahkan hubungan dunia dan akhirat, sebagaimana tertuang dalam Surat Ali Imran ayat 190-191 yang berisi tentang Ulul Albab yang seharusnya bisa menjadi muslim yang cerdas akan ilmu dunia maupun ilmu akhirat sehingga dirinya bisa menjadi lentera bagi kegelapan di sekitarnya.

Pada surah Ali-Imran terdapat konteks tentang Ulul Albab. Hal yang demikian, memiliki makna yang merujuk kepada umat Islam agar menjadi orang yang menggunakan akal pikiran dan keimanan secara maksimal yang sesuai dengan 
tuntunan Al-Qur'an sehingga umat islam bisa menjadi inovator dalam ilmu pengetahuan dan teknologi. Pikiran yang kritis dan inovatif adalah pikiran yang senantiasa berpikir melalui pemikiran yang tajam akan segala hal serta pertimbangannya di berbagai aspek, mampu menganalisis data dan fakta, mampu membuat perkiraan terkait sebuah peristiwa berdasarkan data, memiliki keterampilan dalam menyelesaikan masalah, serta memiliki beragam sudut pandang dan kemampuan memanfaatkan peluang.

Menurut Muhaimin, terdapat lima ciri utama karakter kepribadian generasi ulul albab, yaitu dapat memaksimalkan penggunaan hati dan akal, bertaqwa kepada Allah SWT, memegang keimanan dengan kukuh, gigh dalam menuntut ilmu dunia dan akhirat, serta bisa menjadi pribadi yang bisa menyelesaikan permasalahannya sendiri dan bahkan membantu menyelesaikan permasalahan orang lain. Generasi ulul albab yang akan datang kemungkinan akan lebih banyak berasal dari generasi milenial dengan rentang masa kelahiran yaitu 1982-2004. Dalam perannya, generasi milenial merupakan tonggak penerus perjuangan bangsa yang harus dibina dan diarahkan agar generasi tersebut memiliki kompetensi yang tinggi baik urusan dunia maupun akhirat. Hal itu tentunya akan mencegah terjadinya bom waktu yang bisa menghancurkan sebuah negara jika pemuda/pemudi muslimnya tidak peduli dengan agama mereka.

Oleh karena itu, perlu dilakukan internalisasi nilai-nilai ulul albab seperti dzikir, pikir, dan amal saleh bagi generasi selanjutnya yang akan meneruskan tonggak kepemimpinan baik untuk urusan ilmu dunia maupun ilmu akhirat. Generasi ulul albab sudah seharusnya menjadikan teknologi sebagai alat dan perantara dalam menyelesaikan berbagai permasalahan bukan malah sebaliknya yaitu menjadi budak dari teknologi yang ada. Generasi ulul albab juga memiliki dua karakter khusus, yaitu bisa menjadi individu yang unggul serta sehat jasmani dan rohani. Sudut pandang untuk melihat masalah dari berbagai arah untuk menemukan solusi juga merupakan nilai penting yang harus direalisasikan oleh setiap generasi ulul albab sehingga setiap individu tersebut memiliki sifat dengan aspek seperti spiritual, akhlak, keilmuan, dan profesional yang bisa bermanfaat bagi diri sendiri, lingkungan sekitar, agama, bangsa, bahkan global.

\subsection{Teknologi Dari Perspektif Generasi Ulul Albab}

Kecerdasan buatan adalah teknologi yang saat ini banyak diterapkan pada perangkat elektronik khususnya komputer. Para pakar ilmu komputer telah melakukan banyak penelitian dan pengembangan untuk menyimulasikan kecerdasan buatan yang ditanamkan pada teknologi lainnya agar bisa meniru kecerdasan manusia dalam menyelesaikan berbagai persoalan. Bahkan, perangkat yang dibekali sistem kecerdasan buatan pada saat ini banyak yang telah melampaui kecerdasan manusia secara individu. Pada intinya, sebuah sistem atau perangkat yang dibekali dengan kecerdasan buatan membuat sistem atau perangkat tersebut diharapkan memiliki kemampuan memahami segala sesuatu dengan meniru mekanisme kerja otak manusia sehingga sistem atau perangkat tersebut dapat berperilaku layaknya manusia. Contohnya adalah pada saat pandemi COVID-19, banyak umat islam di dunia yang terkena penyakit COVID19. Generasi ulul albab harus inovatif seperti membuat sebuah terobosan di bidang teknologi alat-alat kedokteran yang bisa membantu orang untuk mendeteksi penyakit lebih cepat dan langsung memberikan solusi agar cepat sembuh dari penyakitnya sehingga para pasien bisa mendapatkan pertolongan yang lebih efektif. Bagi pasien yang muslim, mereka bisa kembali beraktivitas dan beribadah dengan khusyuk tanpa adanya penyakit di tubuhnya.

Generasi ulul albab harus selalu ingat Allah SWT di dalam kondisi atau situasi apapun karena dunia ini hanya sementara dan pencipta alam semesta ini adalah Allah SWT. Jadi, meskipun kita sudah membuat kecerdasan buatan sendiri, jangan pernah berpikir bahwa kita paling berkuasa, tidak percaya tuhan, dan lain-lain, karena perlu diketahui bahwa kecerdasan buatan yang kita buat itu atas kuasa Allah SWT.

\subsection{Dampak yang ditimbulkan dari Teknologi}

Teknologi tidak hanya mendatangkan manfaat tapi juga ancaman. Dilihat berdasarkan data Kejahatan Siber Tahun 2020, ada 1322 laporan masyarakat terkait kasus kejahatan Siber ke pihak Patroli Siber, yang artinya banyak masyarakat yang terkena penyalahgunaan teknologi,

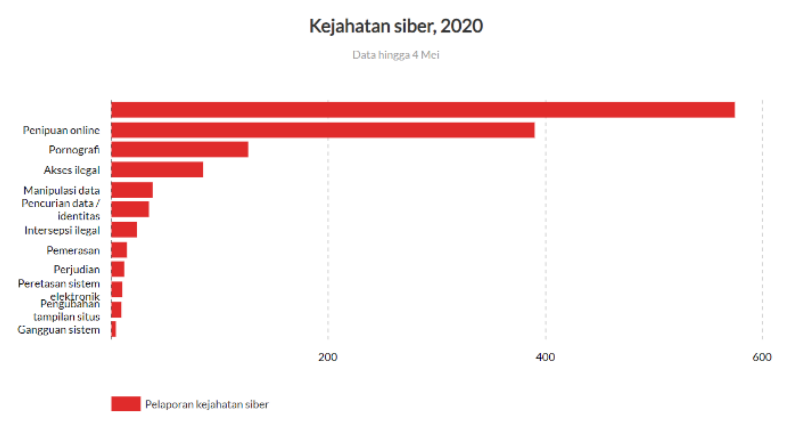

Gambar 16. Data Kejahatan Siber [30]

Padahal jika kita sebagai Generasi Ulul Albab menggunakan Teknologi dengan sebaik-baiknya dan memanfaatkannya ke dalam hal positif, itu sangat berguna sekali untuk kehidupan di masa yang akan datang. Dari data tersebut, Kejahatan penyebaran konten provokatif atau berita hoax sebanyak 575 laporan. Kemudian, kejahatan penipuan online sebanyak 390 laporan dan yang ketiga kejahatan pornografi sebanyak 126 laporan. Kejahatankejahatan seperti ini yang harus dibasmi, kita sebagai generasi ulul albab harus bisa membasmi kejahatan siber ini satu per satu yang mana hal ini terjadi ketika kemajuan iptek tidak dibarengi dengan peningkatan imtak (iman dan taqwa).

Dari maraknya kejahatan di dunia maya yang merupakan bagian dari iptek, membuat para pakar terus berinovasi di 
salah satu bidang iptek dalam mengembangkan sistem yang lebih baik dan aman, khususnya dalam menjaga kerahasian data. yaitu penerapan artificial intelligence dalam kegiatan transaksi data yang mana telah dibahas sebelumnya bahwa sistem kecerdasan buatan tidak diprogram secara eksplisit untuk mengenali sebuah gambar pada computer vision, maka teknologi ini akan sangat membantu dalam merealisasikan sistem yang aman. Tidak hanya itu, dalam dunia medis pun kemampuan computer vision akan sangat dibutuhkan dalam mendeteksi berbagai penyakit dengan lebih akurat sehingga dapat mempercepat proses penyembuhan. Bahkan yang sudah ada sekarang adalah mobil dengan sistem autopilot yang menerapkan computer vision untuk memantau setiap objek yang dilalui di jalan raya. Itu semua adalah dampak positif dari teknologi yang seharusnya bisa lebih ditingkatkan oleh generasi ulul albab agar orientasinya tidak hanya sekadar memberikan kemudahan dalam urusan dunia tapi juga akhirat

\section{KESIMPULAN}

Teknologi kecerdasan buatan akan selalu berkembang dan menuju arah yang semakin canggih. Pemahaman manusia mengenai dirinya di masa depan akan tergantikan oleh robot dengan kecerdasan buatan tidaklah sepenuhnya benar. Kecerdasan buatan tidak hanya terdapat pada robot, melainkan terdapat juga pada perangkat yang selalu kita gunakan seperti smartphone. Robot ataupun sistem kecerdasan buatan hanyalah sebuah alat yang akan memudahkan manusia modern menyelesaikan permasalahan yang sangat kompleks. Manusia itu sendirilah yang menciptakan zaman kecerdasan buatan dengan tujuan memajukan peradaban dengan teknologi digital sehingga manusia jugalah yang akan menjadi commander dalam menentukan arah perkembangan teknologi di dunia.

Seharusnya kemajuan peradaban manusia dan kemudahan dalam mengakses berbagai teknologi yang ada tidak membuat manusia khususnya umat islam menjadikannya terpisah dengan agama. Namun, pada kenyataannya kita masih melihat dampak buruk yang ditimbulkan oleh segelintir manusia yang justru menggunakan teknologi yang telah dikembangkan untuk hal yang tidak baik karena kemajuan tersebut tanpa diiringi dengan peningkatan iman dan taqwa kepada Allah SWT.

Adanya Teknologi pun juga mempunyai dampak positif dan negatifnya. Berdasarkan data yang ada, dampak negatifnya adalah penipuan online, penyebaran hoax, dan lain-lain. Dampak positifnya adalah manusia menjadi lebih produktif untuk membuat suatu inovatif tentang teknologi. Banyak barang-barang di sekitar kita yang sudah terbuat dari teknologi, seperti mobil dengan autopilot menggunakan artificial intelligence, gardu tol menggunakan mesin, dan lain-lain.

Oleh karena itulah kita sebagai generasi ulul albab yang tidak hanya berilmu tetapi juga bertakwa harus bisa menjadi pionir dan inovator yang turut memberikan kontribusi yang nyata dan berguna dalam perkembangan teknologi kecerdasan buatan di dunia karena sesungguhnya muslim yang cerdas adalah muslim yang bisa menjadikan agama dan ilmu pengetahuan bersatu padu dalam kehidupannya.

\section{Daftar Pustaka}

[1] S. Bharati, T. Khan, P. Podder, and N. Hung, "A Comparative Analysis of Image Denoising Problem: Noise Models, Denoising Filters and Applications," in Studies in Systems, Decision and Control, 2020, pp. 49-66. doi: 10.1007/978-3-030-55833-8_3.

[2] I. N. Junejo and N. Ahmed, “A multi-branch separable convolution neural network for pedestrian attribute recognition," Heliyon, vol. 6, no. 3, p. 2, Mar. 2020, doi: $\underline{10.1016 / j . h e l i y o n .2020 . \mathrm{e} 03563 .}$.

[3] L. Datta, "A Survey on Activation Functions and their relation with Xavier and He Normal Initialization," arXiv:2004.06632 [cs], Mar. 2020, Accessed: Nov. 18, 2021. [Online]. Available: http://arxiv.org/abs/2004.0632

[4] M. R. R. Budianto, S. F. Kurnia, and T. R. S. W. Galih, "Perspektif Islam Terhadap Ilmu Pengetahuan dan Teknologi," Islamika, vol. 21, no. 01, pp. 55-61, Aug. 2021, doi: 10.32939/islamika.v21i01.776.

[5] S. SHARMA, "Activation Functions in Neural Networks," Medium, Jul. 04, 2021. https://towardsdatascience.com/activation-functionsneural-networks-1cbd9f8d91d6 (accessed Nov. 18, 2021).

[6] F. Sultana, A. Sufian, and P. Dutta, "Advancements in Image Classification using Convolutional Neural Network," 2018 Fourth International Conference on Research in Computational Intelligence and Communication Networks (ICRCICN), pp. 122-129, Nov. 2018, doi: 10.1109/ICRCICN.2018.8718718.

[7] Al-Qur'an dan Terjemahannya, vol. 4. Al-Akhyar, 2015.

[8] P. S, "Artificial Neural Networks - Better Understanding!," Analytics Vidhya, Jun. 14, 2021. https://www.analyticsvidhya.com/blog/2021/06/artificialneural-networks-better-understanding/ (accessed Nov. 18, 2021).

[9] M. Z. Asghar, M. Abbas, K. Zeeshan, P. Kotilainen, and T. Hämäläinen, "Assessment of Deep learning Methodology for Self-Organizing 5G Networks," Applied Sciences, vol. 9, no. 15, Art. no. 15, Jan. 2019, doi: 10.3390/app9152975.

[10] S. Savalia and V. Emamian, "Cardiac Arrhythmia Classification by Multi-Layer Perceptron and Convolution Neural Networks," Bioengineering (Basel), vol. 5, no. 2, p. 35, May 2018, doi: 10.3390/bioengineering5020035.

[11] M. Pirhooshyaran and M. Yetkin, "Convolutional Neural Network (CNN): Basics and Recent Advancements," OptML Meetings, pp. 5-31, Sep. 2019.

[12] Y. Chen, L. Xu, K. Liu, D. Zeng, and J. Zhao, "Event Extraction via Dynamic Multi-Pooling Convolutional Neural Networks," in Proceedings of the 53rd Annual Meeting of the Association for Computational Linguistics 
and the 7th International Joint Conference on Natural Language Processing (Volume 1: Long Papers), Beijing, China, 2015, pp. 167-176. doi: 10.3115/v1/P15-1017.

[13] V. Verdhan, "Image Classification Using LeNet," in Computer vision Using Deep learning: Neural Network Architectures with Python and Keras, V. Verdhan, Ed. Berkeley, CA: Apress, 2021, pp. 67-101. doi: 10.1007/9781-4842-6616-8_3.

[14] W. S. Eka Putra, "Klasifikasi Citra Menggunakan Convolutional Neural Network (CNN) pada Caltech 101," JTITS, vol. 5, no. 1, Mar. 2017, doi: 10.12962/j23373539.v5i1.15696.

[15] A. Ng, "Machine learning - Non-linear SVM classification with kernels," Open Classroom Standford $E d u$, 2017.

http://openclassroom.stanford.edu/MainFolder/DocumentP age.php?course $=$ MachineLearning \&doc $=$ exercises/ex 8/ex 8 html (accessed Nov. 18, 2021).

[16] M. P. Kuchera et al., "Machine learning methods for track classification in the AT-TPC," Nuclear Instruments and Methods in Physics Research Section A: Accelerators, Spectrometers, Detectors and Associated Equipment, vol. 940, pp. 156-167, Oct. 2019, doi: 10.1016/j.nima.2019.05.097.

[17] L. Leong, "Machine learning Pipelines: Nonlinear Model Stacking," Medium, Jul. 29, 2019. https://towardsdatascience.com/machine-learningpipelines-nonlinear-model-stacking-668f2b720344 (accessed Nov. 18, 2021).

[18] J. Nagi et al., "Max-pooling convolutional neural networks for vision-based hand gesture recognition," Nov. 2011, pp. 342-347. doi: 10.1109/ICSIPA.2011.6144164.

[19] N. Kang, "Multi-Layer Neural Networks with Sigmoid Function-Deep learning for Rookies (2) | by Nahua Kang | Towards Data Science," Towards Data Science, Jun. 27, 2017. https://towardsdatascience.com/multi-layer-neuralnetworks-with-sigmoid-function-deep-learning-forrookies-2-bf464f09eb7f (accessed Nov. 18, 2021).

[20] Z. Liao and G. Carneiro, "On the Importance of Normalisation Layers in Deep learning with Piecewise Linear Activation Units," arXiv:1508.00330 [cs], Nov. 2015, Accessed: Nov. 18, 2021. [Online]. Available: http://arxiv.org/abs/1508.00330

[21] M. Munir, "Membingkai Kepribadian Ulul Albab Generasi Milenial," TA'LIMUNA, vol. 7, no. 1, p. 45, Aug. 2018, doi: $10.32478 /$ ta.v7i1.147.

[22] C. Anam and M. Y. A. Bakar, "Pemikiran Imam Suprayogo Dalam Integrasi Ilmu Keislaman Dan Sains Berbasis Ulul Albab," Madinah: Jurnal Studi Islam, vol. 8, no. 1, Art. no. 1, Jun. 2021.

[23] D. Fermansah, "Penggunaan Metode Traditional Transformations Data Augmentation Untuk Peningkatan Hasil Akurasi Pada Model Algoritma Convolutional Neural Network (Cnn) Diklasifikasi Gambar," sarjana, Universitas Siliwangi, 2019. Accessed: Nov. 18, 2021. [Online]. Available: http://repositori.unsil.ac.id/233/
[24] K. Rana, "Pooling Layer - Beginner To Intermediate," Medium, Apr. 20, 2020. Https://Ai.Plainenglish.Io/Pooling-Layer-Beginner-ToIntermediate-Fa0dbdce80eb (Accessed Nov. 18, 2021).

[25] S. Ganesh, "Weights and Bias in a Neural Network | Towards Data Science," Towards Data Science, Jul. 25, 2020. https://towardsdatascience.com/whats-the-role-ofweights-and-bias-in-a-neural-network-4cf7e9888a0f (accessed Nov. 18, 2021).

[26] Z. HY, "Introduction to Deep learning," Mobile Monitoring Solutions. https://mobilemonitoringsolutions.com/introduction-todeep-learning/ (accessed Dec. 10, 2021)

[27] R. P. Yaniawati, "Penelitian Studi Kepustakaan,” p. 31, Apr. 2020.

[28] A. Yanuar R, "Artificial Neural Network (ANN) Universitas Gadjah Mada Menara Ilmu Machine learning." https://machinelearning.mipa.ugm.ac.id/2018/05/24/artifici al-neural-network-ann/ (accessed Dec. 10, 2021).

[29] "Hidden Layer," DeepAI, May 17, 2019. https://deepai.org/machine-learning-glossary-andterms/hidden-layer-machine-learning (accessed Dec. 10, 2021).

[30] "Kejahatan siber, 2020," https://lokadata.beritagar.id/, May 04, 2020.

https://lokadata.beritagar.id/chart/preview/kejahatan-siber2020-1588564923 (accessed Dec. 11, 2021).

[31] R. Ayunda, "Perlindungan Data Nasabah Terkait Pemanfaatan Artificial Intelligence dalam Aktivitas Perbankan di Indonesia," vol. 7, p. 15, 2021.

[32] A. Geron, Hands-On Machine learning with ScikitLearn, Keras, and TensorFlow, 2nd Edition, 2nd ed. O’Reilly, 2019.

[33] R. Atienza, Advanced Deep learning with TensorFlow 2 and Keras, 2nd ed. Packt Publishing, 2020.

[34] A. F. Gad Menoufia, Practical Computer vision Applications Using Deep learning with CNNs, 1st ed. 2018. [Online]. Available: https://doi.org/10.1007/978-1-48424167-7 